angiography even with a scanning laser ophthalmoscope provides little information about choroidal and choriocapillaris blood flow. This is particularly so in CMO where the thickened retina masks the choriocapillaris completely. It is tempting to speculate that CMO only occurs when retinal pigment epithelial function is seriously and permanently compromised by choroidal ischaemia. This would explain why diffuse CMO does not respond to grid photocoagulation. Chronic CMO is more common in older onset diabetics. ${ }^{11}$ This could be as a result of the choroid in such patients being more ischaemic than in young patients. Severe CMO can occur in young diabetics after extensive panretinal photocoagulation $^{12}$ or as part of pre-proliferative retinopathy. However, it usually clear spontaneously in such cases possibly because of an underlying healthy choriocapillaris.

Hopefully, indocyanine green angiography with a scanning laser ophthalmoscope will provide information on choroidal blood flow in diabetics to allow these questions to be answered in the near future.

DECLAN W FLANAGAN

Addenbrooke's Hospital,

Cambridge CB2 2QQ
1 Bresnick GH. Diabetic macular oedema. A review. Ophthalmology 1986; 93: 989-97.

Fine BS, Brucker AJ. Macular oedema and cystoid macular oedema. Am f Ophthalmol 1981; 92: 466-81.

3 Bresnick GH. Diabetic maculopathy; a critical review highlighting diffuse macular oedema. Ophthalmology 1983; 90: 1301-17.

4 Cox SN, Hay E, Bird AC. Treatment of chronic macular oedema with acetazolamide. Arch Ophthalmol 1988; 106: 1190-5.

5 Olk RJ. Modified grid argon (blue-green) laser photocoagulation for diffuse diabetic macular oedema. Ophthalmology 1986; 93: 938-50.

6 Kearns M, Hamilton AM, Kohner EM. Excessive permeability in diabetic maculopathy. Br ₹ Ophthalmol 1979; 63: 489-97.

7 Aiello LM, Rand LI, Briones JC. Non-ocular clinical risk factors in the progression of diabetic retinopathy. In: Little HL, Jack RL, Patz A, Forsham gression of diabetic retinopathy. In: Little HL, Jack RL, Patz A, Forsham
PH, eds. Diabetic retinopathy. New York; Thieme-Stratton, 1983; 21-32. 8 Clark JB, Grey RH, Lim KK, Burns-Cox CJ. Loss of vision before ophthalmic referral in blind and partially sighted diabetics in Bristol

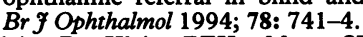

9 Klein R, Klein BEK, Moss SE, Cruikshanks KJ. The Wisconsin Epidemiological Study of diabetic retinopathy. XV. The long term incidence of macular oedema. Ophthalmology 1995; 102: 7-15.

10 The Diabetes Control and Complications Trial Research Group. The effect of intensive treatment of diabetes on the development and progression of long trm N Engl 7 Med 1993; 329: 977 86 .

11 Klein R, Klein BEK, Moss SE. Visual impairment in diabetes. Ophthalmology 1984; 91: 1-8.

12 Nasrallah FP, Jalk AE, von Coppennole F, Masanori K, Trempe CL, McMeel JW, et al. The role of the vitreous in diabetic macular oedema.

$13 \mathrm{MacDonald} \mathrm{HR}$, Schatz $\mathrm{H}$. Macular oedema following pan retinal photocoagulation. Retina 1985; 5: 5-10.

\title{
Visual impairment in children
}

Significant visual impairment in children has long been overlooked and underestimated in terms of prevalence, personal impact, and the social and economic implications. The publication in 1992 by the World Health Organisation (WHO) of 'Prevention of childhood blindness'1 attempted to estimate the extent of the problem and target the issue of prevention. This is a critical issue, as it is estimated that up to $75 \%$ of childhood blindness is preventable or curable. Without access to medical and surgical treatment, the majority of these children will remain with impaired vision. It is imperative that children have access to special education and (re-)habilitation programmes to alleviate the effects of visual deprivation.

The WHO estimates the number of blind children in the world to be 1.5 million with half a million new cases of childhood blindness each year. Based on this figure of prevalence of blindness, Eckstein and colleagues, in a paper in this issue of the $B \mathcal{F O}$ (p 633), have calculated that this accounts for 75 million years of blindness. To the figure of 1.5 million had to be added those children whose vision is impaired to the extent that they are classified as having low vision. From the 1994 WHO update of country statistics on blindness and low vision, 'Available data on blindness', ${ }^{2}$ there are typically three times as many people with low vision as there are blind.

There are difficulties in obtaining accurate data on the prevalence and causes of visual impairment in children. This has been demonstrated in Britain where the survey conducted by the Royal National Institute for the Blind found that the registration figures have grossly underestimated the prevalence of visual impairment in both children and adults. ${ }^{34}$ An approach often used is to survey schools for the blind to establish data for a given area or country. It is more practical to travel to a limited number of sites to examine substantial numbers of children in schools for the blind than to travel to either a large number of schools where a few children are integrated or to visit homes or villages in a population based survey. Care must be taken with generalising data obtained from schools for the blind to the whole country, as the population of the schools is unlikely to be representative of all children with impaired vision. The numbers attending schools for the blind are usually relatively small with greater numbers of students in 'integrated' education and, in developing countries, many or most children may not even attend any school. There are also likely to be children with impaired vision in other special schools for the disabled. The eligibility criteria for enrolment in a school will also influence the degree of impairment of its students and there may also be an unrepresentative sample of the causes of visual impairment, age range, ethnic groups, health, and socioeconomic status within a country or region. Any changes in educational policy and practice will make it difficult to compare data over a period of time.

Although vision screening to establish prevalence data on blindness and low vision can be carried out in the community by health workers, it is more difficult to collect information on the causes of visual impairment. This can only be determined after an ophthalmic examination. Strategies for prevention need to be based on knowledge of the causes of impaired vision. The survey reported in this issue, which was conducted in Sri Lankan schools for the blind, used the WHO/PBL eye examination record for children with blindness and low vision form. ${ }^{5}$ This useful new form records comprehensive information on each child as to the extent and cause of impaired vision. 
In Sri Lanka hereditary disease accounted for $35 \%$ of vision loss. This is within the range (30-70\%) typically found in industrialised countries. ${ }^{1}$ In developing countries hereditary disease usually accounts for relatively smaller percentages of childhood visual impairment because factors such as malnutrition and lack of health care lead to an excess of acquired causes predominantly from corneal scarring. With economic and health services development, acquired eye diseases such as ophthalmia neonatorum or xerophthalmia, for example, become less common.

An additional and often unexpected benefit of a survey of students in schools for the blind is the identification of students who still have usable vision, but who have been educated using non-visual methods such as braille. In the schools for the blind in Sri Lanka, $26 \%$ of the children had moderate or severe low vision (best VA $<6 / 18-3 / 60)$. Even a substantial number of students categorised as blind still had usable vision as indicated by their ability to navigate around obstacles. The children may also retain useful vision for other activities of daily living if they can be taught how to use it appropriately.

In the developed countries, teachers and rehabilitation specialists have training in appropriate visual rehabilitation methods. They have access to a range of equipment and devices for people with low vision. It is only very recently that similar materials and devices have become available for use in developing countries. A simple instrument to identify and assess people with low vision has been developed and will be published by the WHO during 1995 . Christoffel Blindenmission (CBM) has developed and produced a range of low cost magnifiers in Kenya which have great potential benefit for people with low vision. The ongoing work of Gilbert and colleagues draws our attention to this important area and highlights what could and should be done. ${ }^{5}$

JILL KEEFFE

Department of Ophthalmology, HUGH R TAYLOR

Low Vision Unit,

Victoria, Australia

1 World Health Organisation. Prevention of childhood blindness. Geneva: WHO, 1992.

2 World Health Organisation. Available data on blindness (update 1994). Geneva: WHO, 1994

3 Walker E, Tobin M, McKennell A. Blind and partially sighted children in Britain: the RNIB survey. Volume 2. London: HMSO, 1992.

4 Bruce I, McKennell A, Walker E. Blind and partially sighted adults in Britain: the RNIB survey. Volume 1. London: HMSO, 1992

5 Gilbert C, Foster A, Negrel A, Thylefors B. Childhood blindness: a new form for recording causes of visual loss in children. Bull World Health Org 1993; 71: 485-9. 